\title{
Teaching general psychiatry to medical undergraduates
}

\author{
Tom Hughes \& Christopher Williams
}

The future of psychiatry lies not only with advances in treatment, but also with the number and quality of undergraduates attracted into psychiatry. As the quality of teaching of psychiatry to undergraduates is probably one of the factors determining choice of a career in psychiatry (Sierles \& Taylor, 1995), it is to be hoped that improved quality of teaching will not only enhance clinical practice and patient care, but also lead to an increase in the numbers of medical students who choose a career in psychiatry.

\section{What to teach}

The General Medical Council requires that a medical undergraduate gains 'core' knowledge, skills and attitudes necessary to perform successfully as a pre-registration house-officer, not as a specialist (General Medical Council, 1993). A challenge facing specialists in all branches of medicine is deciding exactly what knowledge, skills and attitudes are required. Certain things are generally agreed (Sensky, 1994). The pre-registration doctor needs to know how to assess and manage patients with a major mental illness such as schizophrenia, but probably has a greater need to know how to carry out a basic assessment and initiate management of clinical problems commonly found in a general hospital (e.g. mild to moderate anxiety, depression, confusion, alcohol problems, medically unexplained symptoms and deliberate self-harm).

In addition, the undergraduate may study in depth areas of particular interest in a 'special study module' (General Medical Council, 1993). This should allow students to study areas of special interest to them, and will not focus on the immediate requirements of the pre-registration year.

\section{Core curriculum}

The Working Party of the Education Committee of the Royal College of Psychiatrists, in collaboration with the Association of University Teachers of Psychiatry, has put forward recommendations as to what constitutes the core undergraduate psychiatry curriculum (Royal College of Psychiatrists, 1997). These are summarised in Box 1.

\section{How to teach it}

\section{Teaching style}

An essential aspect of medical teaching is that a significant proportion takes place in a clinical setting with real patients. Other traditional teaching methods such as lectures may be supplemented, or replaced, by approaches such as small group teaching and may be problem-based. An example of a problem in psychiatry might be a video-taped interview, or a written description of a presenting complaint, brief history and mental state findings.

\section{Example}

A 28-year-old woman who is five months pregnant threatens to commit suicide. She says that she has been depressed for several weeks and will kill herself unless alternative accommodation is found for her. She looks miserable and describes depressed mood, anxiety, loss of appetite and disturbed sleep.

If a video is used, the first task of the student, or commonly a group of students, led by a teacher, is to identify the important elements of the case and make a brief summarising statement such as the

Tom Hughes is a lecturer in psychiatry and teaches undergraduates and postgraduates at the University of Leeds (Level 5, Clinical Sciences Building, St James's University Hospital, Leeds LS9 TTF). Christopher Williams is a senior lecturer in psychiatry and teaches undergraduates and postgraduates at the University of Leeds. 
Box 1. Recommendations for a core undergraduate curriculum in general psychiatry

\section{Knowledge}

The prevalence, presentation, aetiology and basic management of 'core' psychiatric conditions.

The conditions under which patients may be detained and treated against their will.

Common physical treatments in psychiatry: indications; mechanism of action; unwanted effects.

The principles of psychotherapy.

The range of services and role of professionals in the community and hospital care of the mentally ill.

Common psychiatric conditions in people with learning disability and the range of services available for them.

Core conditions include:

Affective disorders, substance dependence, anxiety, panic and phobias, post-traumatic stress disorder, normal and abnormal grief and adjustment reactions, psychological problems complicating physical illness, acute confusional states, dementias, obsessive-compulsive disorder, conduct and emotional disorders of childhood and adolescence, schizophrenia.

Additional conditions:

Somatic manifestations of psychological distress, eating disorders, psychosexual disorders, disorders of personality, developmental disorders, attention deficit disorders.

Skills

Communicate effectively with the mentally ill, take a history and carry out a mental state examination.

Produce a formulation commenting on differential diagnosis, aetiology, management and prognosis.

Assess family relationships and their impact on family members.

Assess the need for physical investigations and further psychometric assessment.

Assess a patient's potential risk to others.

Assess a patient's suicide risk.

Facilitate referral to more specialist health services.

Attitudes

Demonstrate an empathic understanding of the emotional problems of patients and of the psychological dimension of illness.

Demonstrate a commitment to maximising the social integration of patients with mental health problems and be sensitive to patient concerns about stigma.

Appreciate the importance of multi-disciplinary working in the field of mental health services.

one above (problem formulation). Explanations are suggested by the students for the psychological and physical symptoms reported by the patient and the physiological processes involved. These provide a focus for further history, examination and investigations, information about which is revealed to the students in stages. During discussion, questions will arise that can be used for student self-directed learning. For example, the mechanism of sleep, the symptoms of depression, normal and abnormal responses to stress, the role of stressors in the formation of psychiatric symptoms. In addition, students may try to solve the problem by making a diagnosis and suggesting ways in which the patient can be managed. The advantages of problem-based learning include that it may foster increased retention of knowledge in the long-term; enhance intrinsic interest in the subject matter; promote the transfer of concepts to new problems; and enhance self-directed learning skills (Norman \& Schmidt, 1992).

\section{Human resources}

The consultant, and other members of the clinical team, are important resources. In a busy clinical day, competing demands may cause teaching time and effort to suffer. Universities pay money to National Health Service trusts through 'service increments for teaching' (SIFT) to offset the additional service costs incurred by teaching. If other duties encroach on time available for teaching, there are resource implications which need to be addressed with management. In addition to face-to-face teaching with students, preparation time is required if the effectiveness of teaching is to be maximised. In a clinical teaching session for example, this may be 
time to plan the objectives of the teaching session and how the outcome is to be assessed.

\section{Material resources}

As psychiatry moves into the community, the consultant might ask whether the facilities there are adequate. The minimum requirements for proper undergraduate teaching on a clinical site should be a video recorder and television, overhead projector with an adequate projection screen, and a dry-wipe board with suitable marker pens. A range of interactive computer-based teaching packages are now available. The local medical school may have someone who can advise on these, and the purchase of such resources may be a proper use of SIFT funds. The self-directed learning encouraged by the problem-based approach outlined above requires a well-stocked library.

\section{Time}

Royal medical colleges have called for improvement in the psychological and psychiatric care of medically ill patients (Royal College of Physicians \& Royal College of Psychiatrists, 1995). There will need to be a change in undergraduate teaching if this improvement is to occur. A survey of psychiatry teaching in $13 \mathrm{UK}$ medical schools found almost half the time was spent on major mental illness and psychiatric sub-specialities and little on clinical topics likely to be encountered in the pre-registration year (Sharpe et al, 1996; see Box 1). Pre-registration doctors managing a patient with what is perceived as a physical problem often ignore relevant psychosocial issues (Williams et al, 1997). Part of the explanation for this may be that for many undergraduates, though not for all (Cantwell \& Brewin, 1995; Carr et al, 1996), psychiatry is taught in isolation from the rest of medicine. Greater integration of psychiatry teaching with that of other specialities is desirable (Sharpeet al, 1996). Until this happens, the consultant can make an impact by ensuring more clinical and teaching time is given to psychiatric problems likely to be encountered in the general hospital.

\section{Good practice points}

\section{Administration}

The core curriculum of the medical school should be made available to the undergraduates, and to every clinical teacher. The aims and objectives of the course should be stated clearly and communicated to the undergraduates at the beginning of the course. It can also be helpful for the teacher and student to write down the objectives (knowledge, skills, attitudes) of a particular teaching session and make sure all present know what they are.

\section{Encourage a 'deep' approach to learning}

Avoid overburdening the student with facts. Involve the student in agreeing the goals of their learning and how these should be achieved. A formal 'protected' teaching slot should allow all students based at a particular hospital site to meet the tutor or another designated teacher for an agreed period each week. A timetable of teaching/learning opportunities should be agreed, including time for self-directed learning.

\section{Ensure the undergraduates are aware of what is expected of them}

A 'psychiatry training guide' could be given to each student at the start of a clinical attachment, which makes the broad aims and specific objectives of the attachment clear. This may be accompanied by a clinical check-list or log book with provision for students to record and review their experiences. The training guide should contain core experience which the student must gain and non-core experience the student could gain. The latter need not be restricted to special study modules, but reflect the division of experiences into those which the student must, should or could obtain. This helps the student to prioritise work and fosters an environment where the student begins to take responsibility for his or her own learning.

A disadvantage of such a guide is that it can develop over the years into a mini-textbook, which may inhibit students seeking out information themselves (Cantwell \& Brewin, 1995). The content of the guide should therefore be reviewed at regular intervals.

\section{Focus on clinical problems found in the general hospital}

Many of the patients available for clinical teaching will have a major mental illness, and the general psychiatrist may feel uncertain about his or her expertise in teaching about psychiatric conditions in the medically or surgically ill. The focus of the teaching should be moved away from the specific 
condition, for example, schizophrenia, towards other areas such as those listed in Box 1, such as: issues of consent to treatment; the working of the multi-disciplinary team, and the role of the psychiatrist within it; the impact of chronic illness on family relationships. By doing this more general issues such as the need to offer good psychosocial care are addressed.

\section{Aim to teach transferable skills}

Effective communication is probably the most important skill an undergraduate can develop during the psychiatry placement. Video recording of interviews can help students improve their skills. It can be intimidating for the students to be filmed, and discussion of video of the psychiatrist in an interview can be a useful start. The development of other transferable skills can also be encouraged. For example, in helping the student to develop skill in diagnosis, discussion of the principles of diagnosis in psychiatry can be broadened to include the process of diagnosis in medicine generally, and how this process changes with the experience of the doctor (Sackett et al, 1991).

\section{Relevance of psychiatry to other parts of the undergraduate course}

Clear reference to the relevance of psychiatry to the pre-registration year may be particularly useful in helping students to structure and integrate their knowledge. Undergraduate teaching in psychiatry may take place in the fourth year, on a short clinical attachment where students work hard, pass the exam and then move on to the next speciality. Knowledge and skills gained in psychiatry that are not integrated into the rest of the students' clinical practice are less likely to be used. This may be explained by context-dependent learning, which proposes that recall and recognition of previously learned material in a different context from that in which learning took place is impaired (Riccio et al, 1984; Murnane \& Phelps, 1994).

\section{Attitudes are important}

Attitude change is difficult to assess and consequently can receive less attention than knowledge and skills. Students may have had little opportunity in other medical specialities for discussion of issues and exploration of attitudes. Discussion of students' attitudes should be encouraged, particularly those attitudes defined as 'core' by the College (Box 1). Also, the view that to separate physical and mental disorders is misleading and unhelpful is an attitude many would wish to see develop. The importance of an integrated assessment of psychological and physical factors in all patients, not just those seen in psychiatry, should be the cornerstone of psychiatry teaching. In medicine and surgery, the significance of shortness or breath, palpitations dizziness and frequency of urine may be missed until a question such as: "Do you ever feel anxious or panicky?" is asked, thus making sense of these apparently diverse symptoms. The student should be encouraged to begin to ask routine screening questions for psychiatric morbidity in their other medical placements (Williams \& Wilson, 1996). The example of the teacher is the most powerful influence upon the standards of conduct and practice of every trainee (General Medical Council, 1993), and psychiatrists have an important role to play in promoting an integrated biopsychosocial assessment of patients.

\section{Review progress regularly}

Students can experience problems on their psychiatric attachment including practical problems about the placement, learning or understanding difficulties and emotional difficulties. The source of a problem does not always lie only with the student, nor only with the teacher. Regular opportunities should be offered to identify and address problems during the attachment and also to identify and tackle students determined to avoid doing any psychiatry.

Give constructive feedback - first refer to what the student did well. Be specific and descriptive about aspects of the student's performance, for example: 'you accepted that the patient felt depressed without clarifying what she meant by depression'. Offer alternatives, for example, another way of clarifying this is to say to the patient: 'I'm still a bit unsure about what you mean by depression'. Try to help the student develop their own effective interview style, which may not be identical to your own.

\section{Integrated medical curriculum}

Some medical schools may have already responded to the General Medical Council's call for greater integration of the medical curriculum. It is possible to speculate on the changes which might take place 
in others. An innovative approach has been described in which the traditional curriculum themes such as anatomy, physiology and biochemistry of the preclinical years, and the medical specialities of the clinical years are replaced by five subject areas including 'professional skills', 'critical reasoning' and 'the identification, prevention and management of illness' (Carr et al, 1996). Psychiatry is integrated with other clinical specialities and with basic sciences and is taught in all five years. For example, a research paper studied in 'critical reasoning' is as likely to be drawn from psychiatry as another speciality.

Integration in the clinical years may be improved by joint liaison teaching, which may be accompanied by a reduction in time spent teaching psychiatry alone (Roose, 1977; Carr et al, 1996). The form of this teaching is that a group students on another clinical attachment, such as surgery, meet a psychiatrist at regular intervals to discuss psychiatric aspects of a clinical problem. An anecdotal report suggests the response of junior medical staff to this teaching is largely determined by the response of the senior physician (Roose, 1977). There may be difficulties in persuading physicians and surgeons to take part in joint teaching. This might be reduced by identifying those physicians and surgeons who have had some training in psychiatry (Wilder et al, 1978) or those who are known to take a more integrated biopsychosocial view of clinical problems, where they exist.

Psychiatrists can also encourage the view that physical and psychosocial factors are important in managing the patient by asking students to cover both in case presentations and clinical teaching. If students are to believe we are serious about this, we must reinforce this by showing this not only in the way we teach medicine, but also in the way we assess students' clinical skills. In practice this may mean asking about psychosocial factors in clinical and written examinations, not just in psychiatry, but also in general medicine, surgery, obstetrics, etc. (Carr et al, 1996). The importance of focusing on a broad biopsychosocial assessment in finals examinations could help overcome the present compartmentalisation of teaching and assessment where exams are sat and then quickly forgotten.

\section{Disadvantages of an integrated medical curriculum}

Some of these have been set out by Werner (1983) and Carr et al (1996). Some areas of the current curriculum may not be covered, and the demands on psychiatrists are likely to increase. The demands on consultants with experience in liaison psychiatry may be particularly great, at a time when a large increase in their number is difficult to forsee. The administrative work in integrating teaching for undergraduates in a variety of clinical settings is likely to be greater, and modification of teaching content is more difficult because of the impact on other disciplines. Some students may find the lessdefined structure of an integrated curriculum overwhelming, and be faced with a greater burden of examinations. Finally, psychiatry would always have to compete with other subjects for the students' attention.

\section{Current status of teaching in universities}

Universities serve two masters, research and teaching. The recent Research Assessment Exercise graded universities according to the quality and quantity of their research output and allocated money accordingly. Some universities may encourage gifted teachers to focus on teaching, but many staff are under pressures to focus on research so that teaching is delegated to the most junior and least experienced. Unless the quality of teaching assessed in the forthcoming Teaching

Box 2. Check-list for the consultant

First week

Meet the student and negotiate the aims and objectives of the clinical attachment

Timetable drawn up (e.g. ward work, clinics, domicillary visits, teachings etc)

Special study module (what is

expected, possible topics)

Student aware of whom to contact in

the event of problems

Middle week

Review of progress (e.g. knowledge/

skills/attitude/attendance/

problems)

Contact medical school if

problems are significant (e.g. poor

attendance)

Final week

Final feedback on performance to student

Obtain feedback on placement

from student 
Quality Assessment Exercise is reflected in financial rewards, the experience students have in psychiatry may be impoverished and the overall academic approach to the teaching of psychiatry may be weakened.

\section{Conclusions}

Changes are taking place in the way medical undergraduates are taught, placing greater emphasis on the requirements of the pre-registration houseofficer. These changes are taking place concurrently with other major changes in psychiatry. This adds to the challenges faced by the consultant and may have resource implications. Changes in medical school curricula should lead to greater integration with other medical specialities. The consultant can make an impact by moving the focus of teaching so that, although major mental illness remains important, the attention given to clinical problems found in the general hospital is increased. The status of teaching in the universities might be improved if financial rewards are given for effective teaching.

\section{References}

Carr V. J., Hazell, P. L. \& Williamson, M. (1996) Teaching psychiatry in an integrated medical curriculum. Australian and New Zealand Journal of Psychiatry, 30, 210-219.

Cantwell, R. \& Brewin, J. (1995) The new undergraduate curriculum: implementing the changes in Nottingham. Psychiatric Bulletin, 19, 482-484.

General Medical Council (1993) Tomorrow's Doctors; Recommendations on Undergraduate Medical Education. London: GMC.

Murnane, K. \& Phelps, M. P. (1994) When does a different environmental context make a difference in recognition? A global activation model. Memory and Cognition, 22, 584-590.

Norman, G. R. \& Schmidt, H. G. (1992) The psychological basis of problem-based learning: a review of the evidence. Academic Medicine, 67, 557-565.

Riccio, D. C., Richardson, R. \& Ebner, D. L. (1984) Memory retreival deficits based upon altered contextual cues: a paradox. Psychological Bulletin, 96, 152-165.

Roose, L. J. (1977) Teaching psychiatry in medical school. International Journal of Psychiatry in Medicine, 8, 53-61.

Royal College of Physicians \& Royal College of Psychiatrists (1995) The Psychological Care of Medical Patients. Recognition of Need and Service Provision. London: Royal College of Physicians and Royal College of Psychiatrists.

Royal College of Psychiatrists (1997) Core psychiatry for tomorrow's doctors. Psychiatric Bulletin, 21, 522-524.

Sackett, D. L., Haynes, R. B., Guyatt, G. H., et al (1991) Clinical Epidemiology: A Basic Science for Clinical Medicine (2nd edn). Boston, MA: Little, Brown and Co.

Sensky, T. (1994) The place of the psychiatrist in the new undergraduate medical curriculum. Psychiatric Bulletin, 18, 557-559.

Sharpe, M., Guthrie, E., Peveler, R., et al (1996) The psychological care of medical patients: a challenge for undergraduate medical education. Journal of the Royal College of Physicians of London, 30, 202-204.
Sierles, F. S. \& Taylor, M.A. (1995) Decline of US medical student career choice of psychiatry and what to do about it. American Journal of Psychiatry, 152, 1416-1426.

Werner, A. (1983) Symposium on the teaching of psychiatry. USA: Michigan State University. Coming to grips with the psychosocial. British Journal of Psychiatry, 142, 333-339.

Wilder, R., Drucker, J. \& Heefner, J. (1978) Teaching psychiatry in a department of medicine. Journal of Medical Education, 53, 992-994.

Williams, C. \& Wilson, S. (1996) Pre-registration house officers' psychiatric knowledge in practice. Psychiatric Bulletin, 20, 398-400.

Williams, C., Wilson, S., Sims, A. C. P., et al (1997) Impact of medical school teaching on preregistration house officers' confidence in assessing and managing common psychological morbidity: three centre study. British Medical Journal, 315, 917-918.

\section{Multiple choice questions}

1. 'Core' psychiatric conditions defined by the Royal College of Psychiatrists include:
a post-traumatic stress disorder
b schizophrenia
c adjustment reactions
d Charles Bonnet syndrome.

2. Problem-based learning is intended to:

a result in improved retention of knowledge

b make students more interested

c increase student reliance on the teacher

d make teaching easier for the teacher.

3. The General Medical Council has proposed that:

a the factual content of the medical curriculum be increased

b the undergraduate course equips students for specialist practice

c the undergraduate course equips students for the pre-registration year

$\mathrm{d}$ areas of particular interest to the student may be studied as a special study module.

4. Constructive feedback:

a starts with pointing out positive features

b includes negative features

c includes commenting on the student's accent

d focuses on specific points, for example: 'you said ...'

MCQ answers

$\begin{array}{llllllll}\text { 1 } & & \text { 2 } & & 3 & & 4 & \\ \text { a } & \text { T } & \text { a } & \text { T } & \text { a } & \text { F } & \text { a } & \text { T } \\ \text { b } & \text { T } & \text { b } & \text { T } & \text { b } & \text { F } & \text { b } & \text { T } \\ \text { c } & \text { T } & \text { c } & \text { F } & \text { c } & \text { T } & \text { c } & \text { F } \\ \text { d } & \text { F } & \text { d } & \text { F } & \text { d } & \text { T } & \text { d } & \text { T }\end{array}$

